\title{
The virtually extended self: searching for meaning in online worlds
}

\author{
Steve Warren
}

School of Applied Psychology, UCC

The technology we use becomes part of our mind, extending our minds, and indeed ourselves, into the world. (David Chalmers)

\section{The Search for Meaning in Life}

\section{Denton}

A man wakes to the same world that has greeted him every morning for the past 29 years. It's a world he isn't very fond of, and it's a world that hasn't given him much opportunity to change. He lives in practical isolation, caring for his house bound mother, a duty left to him after an abusive father finally left a few years back. He doesn't have a job, nor has he ever. He doesn't have friends in the real world, although he would like some, and he doesn't have a normal life, although this is something he also desires. This is a man who lives with depression and anxiety, in a world where his needs and wants go largely unfulfilled. One day a seemingly insignificant decision, based on his underlying desire for improvement in life, had an outcome that would impact his life as much as, if not more than, any of those forced upon him previously; he purchased World of Warcraft, a massively multiplayer online role-playing game (MMORPG). Suddenly this online world opens up to him, he plays the game from dusk to dawn, and well beyond. He makes friends, starts participating in a community, gets a feeling of accomplishment, gets to express himself, and has control over his life in this world; he begins to grow and experience all the meaningful things life can offer for the first time. This is the story of Denton, and it isn't a unique one.

\section{Decisions}

The decision Denton made, whether he knew it or not, was all part of his own personal search for meaning. Every day we make decisions, small or large, which can either be based on the past or based on the future. If I decide to stay home tonight, I am choosing the past; I know it's comfy, I have done it many times, I liked it before, and so on. It's the safe option. But if I decide to go to the ballet on a whim I am choosing the future; it is a new experience for me, and so previously unknown opportunities arise, and so 
on. Each decision we make each day builds up until an underlying direction is formed, what Sartre called a fundamental project. An underlying direction pointed at the past leads to stagnation, boredom and a sense that life is meaningless. An underlying direction pointed at the future leads to excitement, fulfilment and a sense that life may have some meaning. This time Denton, for whatever reason, decided to choose the future. His search for meaning in life had turned a corner.

\section{Meaning in Life}

So what exactly is meaning in life? Meaning in life is, according to Schnell, 'a fundamental sense of meaning based on the appraisal of one's life as coherent, significant, directed and belonging'. The literature holds that there are the three pillars of meaning in life: 1) that your life has personal significance, that you feel your life is worth something, 2) that your life makes sense, that it has a sense of order, and 3) that your life has a direction, that you feel your life has a definite purpose.

So what exactly is involved in the search for meaning? The search for meaning has been found to be an ever-present facet of our lives, and regardless of the level of presence of meaning in life the search is always ticking over. After reading the paragraph on decisions you shouldn't be surprised to hear that curiosity is a predictor for the extraction of meaning from any given situation or on any given day. Exploration of the self, the world, and the expansion of skills and knowledge lead to a greater chance of meaning being found.

But how do you extract meaning from the world around you? There are what the literature calls sources of meaning, these are the cognitive and emotional resources that an individual draws upon to obtain meaning in life. Some examples of these would be; knowledge, challenge, individualism, achievement, and creativity. These are only five of a potential thirty plus sources that can be used to give you that feeling of significance, purpose or order, a feeling of meaning in life. However, there are also domains, or areas of life, that allow you access to these sources. Online gaming is one such domain. It is at this point in the literature where my research aims to make a contribution by finding which of these sources are specific to online gaming, and what the relationship is between online gaming and meaning in life.

\section{Online Games}

\section{Popularity}

Video games in general have permeated our everyday lives, as demonstrated by the fact that it is claimed in 2013 that $67 \%$ of US households play them and that $\$ 66$ billion dollars were spent on gaming. Figures now claim that $72 \%$ of gamers now in 2014 play online, 
with 17 billion hours invested in Xbox Live alone in a single year. Games, and in particular online games, are no insignificant thing.

\section{Extended Minds and Extended Selves}

In the field of philosophy of mind, Clark and Chalmers have discussed the idea of The Extended Mind. This is the idea that some mental processes are extended into the organism's environment; that the mind does not end at the same place your neurons do. So we manipulate, exploit, and transform external structures to use them as extensions of our minds. In a thought experiment, Inga and Otto are trying to recall where the museum is. Otto has Alzheimer's so he writes down as many memories as he can on his notepad. Otto recalls by consulting his notepad, which he has used as an extension of his mind. As humans we do this all the time, from counting on our hands to using an iPhone for memory, navigation, calculations, etc. According to Chalmers, the technology we use "becomes part of our mind, extending our minds, and indeed ourselves, into the world"

$\mathrm{Ng}$ and Wiemer-Hastings found that even if certain MMORPG players could not play in a game. For whatever reason, they would look for social interaction elsewhere online. Some people just prefer the interactions online. Yee discovered that $40 \%$ of males and $54 \%$ of females found their online friends comparable or better that their real life friends. This is not an insignificant number, and shows how important and influential the online world can be.

In one paper, compellingly named The Ideal Elf, it was shown that players who have low self-esteem or depression create characters in online games that are closer to resembling their ideal selves over their real selves. This is based on a theory called self-discrepancy, where a person's happiness is related to the gap between their real self and their ideal self. Therefore, by creating a character online they are filling this gap.

\section{The Virtually Extended Self}

\section{Method}

Based on the literature discussed above, the current study set out to discover the potential relationship between meaning in life and online gaming. This research employed a qualitative approach, by interviews with MMORPG players. Ages ranged between 18 and 42, with both male and females interviewed. Grounded theory was employed to analyse the interviews, chosen because of its systematic methods in discovering a theory that would describe the relationship which was the goal of the research. 


\section{Tools for Meaning}

The theory constructed in the study describes the relationship between a gamer's offline life and their online life. Players of online games, in this case MMORPGs, will use the game to obtain differing amounts of meaning in life through the activity of participating in the online world. However, it is only a temporary benefit, as they understand that the real world is the most important reality. The players seem to use the game as a stepping stone. It was shown that players use the game to get what they want, and do the things they want. The theory then reads:

Players use online games as temporary tools to obtain missing meaning in life

This theory has two important facets; 1) the game/online world (the distinction being blurred here) used as a vehicle to obtain meaning in life, whether inadvertently or otherwise, and 2) that this process is ultimately temporary, and is used as a stepping stone. The online world is a bubble, and in the long run participants say they want the sources of meaning to come from the real world. Booker sums up this idea that the game is used as an extension of the real world:

"The real world is always where the most valuable and deepest experiences will take place.. In conjunction with the real world, then it [gaming] adds a considerable amount."

Elizabeth has an interesting story to tell when it comes to meaning that is missing in life and the potential to replace it. She now lives in a small community, where she is completing her MSc in Clinical Psychology. Unfortunately for her, she feels that she has to be very careful with how she appears in public, in case it affects her professional reputation. She must dress a certain way, speak a certain way, and behave a certain way. She continues:

“... it's very tiring, so WoW let's me be me really".

Her life has taken a turn that, while she is happy with it in one sense, has significant setbacks in another. Her life is now artificially constricted, and she is missing aspects of life which are important to her, such as the ability to be herself. Asked if she felt that the game may help with that issue, she replied:

"Uh yes, it allows me to pull into my life those people I want in it, and leave out those whom I can do without".

Elizabeth uses the game as a tool to do and get the things she wants. The online world is a place where she can be herself and get an important form of personal meaning in life.

Another participant, Manderley, replies to a question about the feeling of accomplishment with the following:

"At the moment, I'm unemployed (and job hunting), so it's definitely happening in WoW more often :) When I was at work, though, I could count on several times a week feeling more accomplished and useful." 
For Manderley, being out of work has meant that he is not getting that feeling of accomplishment and self-worth in the real world he would like, and the game is helping fill that gap. He continues:

"I would say it's a means to interact from home when I don't have the ability to 'get out' - I'm a single dad so my ability to go shoot billiards or have a night out is pretty limited."

For Manderley, just like Elizabeth and many others in the current study, the online world is a way to get and do the things they are unable to do in the real world.

\section{Six Online Sources of Meaning}

The current study found six sources of meaning that an individual has the potential to obtain through participation in the online world. The six factors are: social participation, sense of community, accomplishment, expression, agency, and personal growth. These factors are the sources of meaning that players can obtain from playing online games, and in turn influence the theory discussed above. It is these six factors that players of online games will look to replace by participating in the game, consciously or unconsciously.

\section{Notepads, Computers and Meaning}

Just as Otto used his notepad as an extension of his mind, as an external structure manipulated to extend his mind's abilities, Denton uses the character he has created in the online world as an extension of not only his mind, but his self. William James talked about how we extend into our environments, how our identity is defined by not only the inner self, but also the outer self; our clothes, our car, etc. Chalmers and Clark talk about how we extend our minds into the environment, and use them as tools to improve our "holistic minds."

And for Denton, these both apply. He extends himself into this online world, a relational world, a social world, full of dialogues that spring from and create that world. It is here he searches for missing meaning, using his extended online self to enrich what we might call his "holistic self."

The current study has shown that people who participate in these online worlds consider them, consciously or unconsciously, an enhancer of their whole (or holistic) life experience. People will obtain differing sources of meaning from their participation in the online world, with the strength of attainment depending on what they are missing in the real world. It can be something as simple as fun or social activity, to as complex as agency or expression. They use the online world as a tool to obtain missing meaning in life. 
However, it is important to note that the online world is not used as a replacement for the real world, but rather as an enhancement. People who involve themselves in these online worlds believe that the real world is still the most important arena, but due to circumstances, often out of their control, they must expand their search. This is a salient point, as it has been argued many times that spending time in online worlds is a waste of time, and people who use them should be made interact in the real world. That online worlds are unhealthy and objectively inferior to the real world, but these arguments miss the point. The online world is different to the real world. At present, the online world can be viewed as something like a crutch; it is something we rely on when our preference for the real is unavailable. You don't walk up to someone using a crutch and demand they throw it away and walk on their broken leg. The crutch, just like an online world, is an enhancer of our holistic life experience. But as access to and advancements in the online world continue, this idea that the online world can be used to enhance experience will become even more important, maybe even to the point where the online world may not be regarded as a crutch at all, where the difference between the online world and the real world is practically indistinguishable because of the tight integration between the two.

I would like to thank my supervisor, Dr. Jurek Kirakowski, as well as all the participants who kindly agreed to take part in my study. 